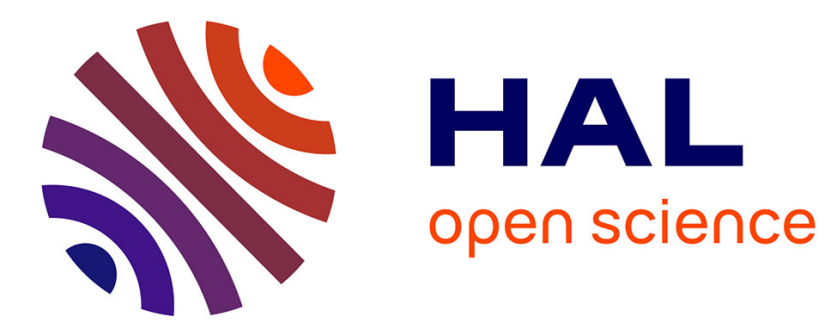

\title{
Flame Wars on Worldnet: Early Constructions of the International User
}

Christopher Leslie

\section{To cite this version:}

Christopher Leslie. Flame Wars on Worldnet: Early Constructions of the International User. IFIP International Conference on the History of Computing (HC), May 2016, Brooklyn, NY, United States. pp.122-140, 10.1007/978-3-319-49463-0_9 . hal-01620137

\section{HAL Id: hal-01620137 \\ https://hal.inria.fr/hal-01620137}

Submitted on 20 Oct 2017

HAL is a multi-disciplinary open access archive for the deposit and dissemination of scientific research documents, whether they are published or not. The documents may come from teaching and research institutions in France or abroad, or from public or private research centers.
L'archive ouverte pluridisciplinaire HAL, est destinée au dépôt et à la diffusion de documents scientifiques de niveau recherche, publiés ou non, émanant des établissements d'enseignement et de recherche français ou étrangers, des laboratoires publics ou privés.

\section{(c)(1)}

Distributed under a Creative Commons Attribution| 4.0 International License 


\title{
Flame Wars on Worldnet: Early Constructions of the International User
}

\author{
Christopher Leslie \\ New York University Tandon School of Engineering, Brooklyn, NY, USA \\ chris.leslie@nyu.edu
}

\begin{abstract}
Some of the earliest users of the Internet described their activities as predicting a widespread communication medium that would cross national boundaries even before the technical capability was possible. An analysis of conversations on Human-Nets, an early ARPANet mailing list, shows how users were concerned about providing a forum for open discussion and hoped that the network would spread to provide communication throughout the world. Moving forward to CSNET, one can also see a strong insistence that the network provide connectivity beyond the United States. Contrary to those who might tell the history of the Internet as a story of a technology that was first perfected by the military, adapted by U.S. academics and then brought to the rest of the world in the 1990s, these users reveal a strong ideology of international communication.
\end{abstract}

Keywords. ARPANet, Internet, Human-Nets, CSNET, e-mail

\section{Introduction}

The story of the internationalization of the Internet is sometimes told as if the technology diffused on its own merit without anyone having to act: packet-switching and TCP/IP were developed for ARPANet, the story goes, and once routers were perfected for NSFNET, the Internet went worldwide in the 1990s. The rapid increase of Internet users after the development of the WorldWideWeb, in particular, makes it seem as if the Internet was just a good idea that attracted the attention of many users quickly, crossing national boundaries after it was perfected. Nevertheless, one can see from ARPANet mailing list discussions that even before there was the technical possibility to extend the network to other countries, there was the desire to do so. The high regard the ARPANet community placed on the power of online communication and the potential it saw to transcend national boundaries was on their minds before connections went international. From this, one suspects that the diffusion of Internet communication was a preliminary design consideration rather than something that occurred after the design was perfected.

An agentless diffusion of technology, certainly, contradicts the central place Science and Technology Studies (STS) accords to users. STS practitioners are averse 
to deterministic interpretations; technological advances do not, an STS scholar would argue, spread through the world of their own accord. An agentless dissemination of the printing press, for instance, would say that the rapid increase in European literacy shows how a device transforms society on its own; however, analysis reveals that a cultural substrate already existed in the form of book markets where hand-copied texts were sold (see [1] for instance). If the pre-existing demand for books helps to explain the rapid diffusion of the printing press, what analogous substrate can be said to have paved the way for international demand for the Web-enabled Internet?

One pre-existing network that can be seen as an important preparation for the Web-based Internet was CSNET, which connected computer science departments without defence research contracts to the ARPANet in the 1980s. CSNET's ethic of international collaboration was an indicator of the kind of activity that shows how individual users, working with a common goal, would be important in distributing the knowledge and experience needed for the eventual success of the Worldwide Web. This is not to say that CSNET was the only mechanism that worked to this end; certainly other networks (USENET, BITNET, MERIT, Télétel and its relatives, and Telenet, to name a few) were important in this regard. CSNET, however, offers insight into the technical community's international ideals and aspirations. The motivation behind this cosmopolitan ideal can be seen in the early ARPANet discussion group Human-Nets. This list, one of the first networked discussion groups, was devoted to the future of computer networks and is a rich resource that one can use to gain insight into what ARPANet users thought about the tools they were using. In particular, in the so-called flame wars and the meta-discussions of how to deal with group communication by electronic mail, one can see how ARPANet users immediately embraced the ideals of free and open connections.

In the late 1970s, as the ARPANet was coming into its own and the first tests of what would become TCP/IP were being conducted, users communicated by what today we would call e-mail in interest groups that predicted USENET and other email groups. In RFC 541, these messages were conceived of as text messages sent by file transfer protocol (FTP) and were simply called mail and RFC 822 refers to them as Internet text messages, even though the protocols they utilized were behind what today we think of as e-mail. A fairly well-known anecdote about the careful attention to the quality of conversation on these channels relates to the claim of Quasar Industries that it was about to mass-produce service robots came to the attention of the ARPANet community. Concerned that what they were seeing was a fraudulent claim, a debate emerged on electronic discussion lists.

Quasar's claim is noted as a hoax by Hafner and Lyon's Where Wizards Stay Up Late [2] and more recently in Finn Brunton's Spam [3]. However, the hoax went unquestioned in the business press and even in one academic text [4]. Alan Abelson reported in 1979 that at the Ninth Davos Symposium, which had the theme preparing for the changes of the 1980s, Quasar president Anthony Reichelt presented one of his "people-looking robots" that would be manufactured for security, sales, domestic help, and even psychotherapy. "Extremely good results have been achieved in communication with autistic children," Abelson wrote [5]. "A Robot in Every Home," Changing Times proclaimed in 1978. A domestic android would be offered for $\$ 4,000$ 
and a $\$ 45$ per month service contract. The android would answer the door, fix drinks, vacuum, and guard against fires and burglars [6]. "Quasar Industries, for example, has a domestic robot in production for 1980 which will perform many tasks around the house generally assumed to be the human" [7]. Given the professional interests of the people on ARPANet, it is not surprising that these claims garnered attention and criticism. What is more interesting, though, was how events like these fostered debates about the debate. As detailed below, the meta-discussion about the role of online communication and the potential for its abuse offers an intriguing glimpse into the aspirations of the community that was developing TCP/IP.

Although user activity on the early network is not thoroughly studied, it is important in several respects. Given that CSNET was funded by the National Science Foundation, it can safely be said that the project helped the NSF internally for the more widespread development of NSFNET at the end of the decade. Additionally, there were significant technical developments made in the network, including the creation of software libraries and a patch that allowed TCP/IP packets to be sent over the alternative X.25 pipes, which would help provide a motivation to get onto the Net and facilitate the means to do so. Finally, however, it is notable that many international TCP/IP connections were fostered by CSNET, which is something of a paradox. CSNET was developed to help U.S. academic researchers in computer science join together as a community, not as a project for international diplomacy. What, then, was the motivation behind the diffusion of CSNET to other countries? As it turns out, in the years around the international spread of CSNET, one can find evidence of user sentiment about the online community that would seem to indicate that it was the users, and not the policy makers, who sponsored international connections, and official policy followed in their wake.

The present paper draws attention to the power of users that has been important to the study of the history of computing. Janet Abbate, in Chapter 3 of her seminal Inventing of the Internet [8], notes that users transformed the ARPANet to fit in with how they were accustomed to working, resulting in, among other things, mail protocols. The conversation about networking on Human-Nets takes a similar approach. In the same way that Robert Boyle and his contemporaries are described in Leviathan and the Air Pump [9], we see these researchers debating about how debates should take place. In this way, users define the kind of community they expect to develop around computer networks and thus shape the way in which networks develop. This concept nicely supports the STS approach known as social construction of technological systems (SCOTS), especially as summarized in the anthology How Users Matter [10]. Per Lundin, however, has posed an interesting challenge in his Computers in Swedish Society: Documenting Early Use and Trends [11]: the users who matter are only a subset of the people who use a system, the insider group that is actively involved in the development of a system. His work seeks to document the middle ground of what he calls elite users, the ones behind the public figures and the masses of end users who passively (or, as Lundin states, perhaps resentfully) are the users of a system.

Building on Lundin's insight, this paper tells the story of CSNET in the context of reports from users of computer networks. Where Lundin has attempted to "build a 
history from below" by creating archival documents through interviews, however, we have been interested in using a different sort of documentary evidence: the records left by elite users regarding their efforts and challenges to form discussion networks. Looking at the archives of the Human Nets mailing list from the 1980's and analysing the content to quantify how many posters initiated discussion about how debates on the list should operate is one aspect of the analysis; in addition, qualitatively investigating the attitudes and ideals of this community in another. The sentiment found was not fundamentally different from today's Internet users. This was an online community where any discussion was welcome, where people fought for freedom of speech and shared knowledge and information. In this way, this paper juxtaposes the story of the internationalization of Internet technology via CSNET with a contemporary dataset of insights from computer users. The international effort to spread connectivity is interesting because it demonstrates the power of the computing professionals to form a community defined on the profession, rather than state identity, in an era when computing projects were largely funded by national governments.

\section{A Genealogy of CSNET}

Hafner and Lyon [2] suggest that CSNET was created to avoid a sort of digital divide. The ARPANet in 1979 had 61 nodes, 15 of which were at universities, even though there were around 120 computer science departments nationwide. A connection to ARPANet meant access to shared files, remote login to services, and by 1979 a growing number of electronic messaging groups where the latest ideas could be discussed. Departments such as that at Purdue University, where the vice president of the ACM, Peter Denning, worked, felt as if they were being left out of the loop. Top faculty and graduate students seemed drawn to universities with ARPANet connections, meaning that universities that did not have the political connections, finances (an ARPANet site cost $\$ 100,000$ just to set up), and defense contracts were in danger of being left behind - not to mention that academics had a much better chance of gaining access to the network and advanced computer facilities by leaving the university altogether and moving to an industrial site.

In order to address this gap, Larry Landweber from the University of Wisconsin made a proposal to the National Science Foundation for a network of universities and corporations that did not have ARPANet access [12]. Although he was not a networking expert, Landweber was no newcomer; he had previously worked with the NSF on a project called THEORYNET to provide researchers in theoretical computer science email access. His final proposal for CSNET in 1980 had a three-tier system funded by a $\$ 5$ million grant. The lowest level of connectivity was offered by PhoneNet, a store-and-forward service that allowed email connections over periodic phone calls; unlike the growing Usenet service, however, PhoneNet email could be sent to ARPANet addresses. X25Net was a middle tier, allowing users to run TCP/IP packets over leased lines using X.25 so that they could access FTP and Telnet via a connection at Madison. For a few sites, such as Landweber's department as well as 
Purdue and the RAND Corporation, full ARPANET connectivity was offered. The rapid spread of CSNET speaks to the widespread use of computer networks at the time. CSNET was originally an acronym for "computer science research network," but once computer scientists had widespread connectivity, other science fields asked for access and were "urged to use the mechanisms already available." For this reason, the name of the network changed to the "computer and science network" [13]. By 1982, there were 75 PhoneNet subscribers.

CSNET was an early proponent of international connections even in the troubled years of the Cold War. The first explicitly international connection of CSNET was to Israel in 1982, followed by France, West Germany, and Japan. In spite of a high-tech export ban, Korea and China managed to connect through the effort of academics, and CSNET became a model for the program of international connections sponsored by NSFNET from 1987 to 1994. Even though it was a significant force in the internationalization of the Internet, the initial proposal barely mentions other countries. In fact, CSNET was designed in response to a perceived national "crisis" in computer science, according to the proposal [12]. A shortage of qualified personnel in experimental areas combined with the low availability of software tools due to low productivity and blocks to transporting completed tools had brought the United States to a crisis. According to the proposal, the personnel shortage resulted from competition from industry. The demand for computers had "exponentially" expanded the need for designers and programmers, leading industry to raise salaries to "record levels." Talent was also attracted to industry sites because of their "superior experimental facilities," meaning that students were discouraged from entering PhD programs and those who did complete a $\mathrm{PhD}$ were understandably attracted to industry positions.

Citing various studies around 1980, the proposal indicates that there were around $75 \%$ fewer candidates than postings for faculty positions. The software challenge was due to the different media used by disparate computer systems and the challenge of locating software that had already been developed, which forced researchers "to needlessly redevelop tools or forego promising lines of investigation altogether" [12]. A research network, the proposal asserted, was an essential part of averting this crisis. CSNET's standard protocols for file transfer and its electronic messaging system would facilitate "new cooperative ventures" and thus help to increase software output. Similarly, it would address the personnel shortage by making academic departments more attractive sites for research and allowing "critical masses" of researchers, which would foster collaboration.

Given the funding from the National Science Foundation, the focus on the U.S. situation is perhaps not surprising; the use of tax dollars for cutting-edge research could be expected to advance the interests of the country. In spite of the nationalistic appeal to a crisis, there is no mention of containing CSNET to the United States; although someone familiar with TCP/IP protocols and X.25 networks would realize that international users could connect, someone with less technical savvy might not have realized the potential openness of the network. Other countries, nevertheless, do find their way into the proposal: in assessing the potential impact of the project, the authors cited SAMNET, a message service based at the University of Toronto. In the 
context of the dissemination of technical reports, the proposal notes that an effort by the International Federation for Information Processing (IFIP) to create an online journal, which could be made available to users of CSNET.

The idea of international collaboration, however slight in the proposal, seems to have been on the mind of the project management committee. A report [14] on CSNET's first year of operation, dated 22 July 1982, makes an overt mention of reaching outside of the United States. The Management Committee, headed by Landweber and comprised of Denning (Purdue), Edmiston (BBN), Farber (Delaware), Hearn (Rand), and Kern (NSF) had been in email communication daily and in person about every two months. The report mentions that, beyond day-to-day operations, the committee had been discussing "international collaboration" (CSNET 21).

The network became self-sufficient in five years, according to its goal, but in 1988 it was merged with another network, BITNET, and ceased operation as a separate entity. Because of its short life, it is tempting to skip over CSNET. Even in 1984, a writer on Human-Nets trying to add up the number of users of computer networks remarked:

I think that we can ignore CSNET here (they're all either on USENET or directly on Internet anyway...), so they count for zero.

Certainly, in looking over early mailing list archives, it seems as if many U.S. users display USENET, ARPANet, and CSNET addresses in their signature blocks in the mailing list discussions on HumanNets and SFLovers. For this reason, perhaps, the story of CSNET is sometimes omitted or abbreviated in the history of the Internet, but it is not necessarily in connectivity that CSNET played its important role. Janet Abbate, in Inventing the Internet, notes that after its experience with CSNET, the National Science Foundation began experimenting with networks of its own, leading to NSFNET. On the occasion of the Internet Society's awarding CSNET the Jonathan B. Postel Service Award in 2009, Stephen Wolff [15] remarked,

CSNET was a critical link in the transition from the research-oriented ARPANET to today's global Internet. CSNET also helped lead the way by sharing technologies, fostering connections, and nurturing the worldwide community that provided a foundation for the global expansion of the Internet

\section{Flaming on Worldnet}

Today, an e-mail conversation among a group of people who share a common interest is commonplace, but this use of electronic messages is in fact a development of ARPANet. Ronda Hauben [16] provides a good description of this service:

Also in that year [1975] the MsgGroup mailing list was started to explore the use of the ARPANET for conferencing. Mailing lists were uses of email where each message sent to the list was distributed to all list members. They each could read it and comment by sending a new message which in turn would be sent to all the 
other list members. Very serious and high level results occur. Other mailing lists appeared such as Human-nets for the discussion of the future of ubiquitous networking and SF-Lovers for the discussion of a favorite hobby, science fiction. Participants in these lists were happily surprised how interesting and valuable such network use was.

Richard T. Griffiths [17] notes that there were about 17 groups by the end of the 1970s and that there were 44 by 1982 . Keith Lynch [18] writes that the list was devoted to a discussion about what they called Worldnet: "a hypothetical future worldwide computer network." This is ironic, though, because as noted by Griffiths only users of the exclusive ARPANet could join the conversation. According to Wikibooks, Mark Horton provided a feed from the ARPANet group to USENET in 1980 [19], which allowed others to listen in on the conversation even if they could not send messages back. This shunt of messages helps to provide the first archive of this group and others because USENET messages are better preserved.

The third volume of Human-Nets [20] included issue 98 to issue 112, from May 1981 to June 1981. It had a total of 122 messages, of which 37 were lacking full or real names. Roughly categorizing the topics of discussion yields a profile of the discussion. About 50 messages concerned general information about technology and science, 30 were asking for help or providing assistance, 34 expressed concerns with emerging technologies, 38 explored and discussed interactions between humans and computers, 25 discussed the Human-Nets listserv itself, 22 were creative and artistic, and 8 were announcements of some sort. By examining the times in which a post was a reply to another user, one can see that there were over 20 discussions, but only a few had over 10 or more replies. However, some discussions went into great depth and did not seem to require multiple inputs, whereas some discussion had many replies with very little content in each. The two biggest discussions were about the effect of computer networks on the English language and synthetic chemicals.

The conversation on language was far-ranging and recalls conversations one might have today. For instance, the notion of 'flaming' a user or list appears in the first archived volume when a user apologizes if his 'flame burns anyone.' Several users expressed this word in their experience of using computer jargon in real life. One poster noted that "ITS-ey" jargon had caught on among the poster's parents and friends. A few were interested in the etymology of some words; the habit of marking ranting text as a "flame" came under scrutiny at one point, with posters questioning the etymology of the term. One of the ideas proposed was that flaming came from a homophobic origin: "Flame' in hackerese and 'Flaming' in homophilese," one poster wrote. Another user suggests that the word was not coming from the gay community but the reluctance of some using it reflects their discomfort with the word's connotation. Soon, though, pseudocode turning flames on and off appear and users frequently refer to impassioned speech as flames. In a published article from 1980, Les Earnest [21] proposed an origin that was not related to a gay slur:

The quickness of communication carries with it a problem, however; we have discovered that it is much easier for people to lose their 
tempers in this new form of journalism than in slower systems. The problem clearly arises from perceiving mild disagreements as insults when they are quickly distributed to hundreds of people. This phenomenon has been observed enough times, even involving normally cool-headed people, that it has been given a label: 'flaming.' The Human-nets editor has learned to suppress material that seems to be 'flaming.'

In addition to this discussion there was also a small offshoot discussion about sexist language or terms in the computer lexicon. While these discussions do not gain momentum, their presence in the flow of the conversation about the future of computer-mediated conversation reveal that there was some sensitivity to how outsiders might react to their word choice and an effort to make a more inclusive environment.

The discussion on synthetic chemicals started as inquiry about left-handed (low calorie) sugar and drifted into sci-fi territory of dark matter. The discussion touched chemical structures along the way. Strangely, much of the discussion was low quality, similar to most discussions on the Internet today. However, they were lucky enough to have someone knowledgeable step in and explain away the whole mess. Another big discussion was on colour blindness and how to improve technology for those who are colour-blind. The discussion was not solely focused upon computer usage but as well as sharing personal experiences and discussing potential solutions.

Technology oriented discussion focused primarily on speed of modems and phone lines, as well as the Xerox Star computer. The discussion on the Xerox Star workstation centred mostly on pricing and the computer's specifications. There was also discussion about TV signals, mainly how to descramble them. Most of the discussion on speed was explaining how the lines work and about which lines to acquire. The major complaint was about not achieving the maximum speed. Help was offered with concrete step by step information. The discussion at the end of the volume was about the Human-Nets itself. The discussion about low-calorie sugar and anti-matter caused the moderator to suggest moving such discussion to other mailing lists. But most members replied that discussion and free speech should be encouraged.

These numbers paint a contrasting picture about the Human-Nets: there was a spectrum of dialogue or discussion. At one end, it was purely knowledge-based, and at another end, the content was personal. At this point in the mailing lists, the majority of the posts tended to fall on the former part of the spectrum. The most personal of messages were what today we would call flames, members calling each other out in an aggressive fashion. The most informative messages were about modems and computers. Discussions about the computer science community and the mailing lists were in the middle of that spectrum. This analysis indicates that people preferring computer interaction is not a novel a problem. It has been recognized since the $80 \mathrm{~s}$. There was also curiosity about the user base, of its demographic and social impacts. However, much of this was speculation on Human-Nets because it was difficult to conduct research on an emerging technology. There were questions as to how to poll/survey people, but the results were not listed on the digest. They were placed in files on the mainframe computers and thus were probably lost. 
The discussion on colour-blindness signals the start of ergonomics and attempts to make computing more available to the public. It also demonstrates how mailing lists facilitated exchange of knowledge completely unrelated to computing. Getting off topic was the natural order of things. The exemplary of topic discussion was the low calorie sugar discussion. This discussion also demonstrated that the people who posted on the mailing lists did not know what they were talking about sometimes. When the discussion switched over to dark matter, there was a lot of hearsay. The discussions about modems and lines were extremely detailed. After all, this was their expertise. There were also a lot of people seeking technical help. Unlike the MsgGroup, there was not any moderator comment about criticism on computers and their specs. The people were allowed to bash on the products they did not like. The meta-discussions seem to be the most historically important. It seems that because of the user base, there was not much censorship or moderation. In fact, the moderators did not seem have much power except those given by the users. Overall, Volume 3 shows a basic picture of the early days of the ARPANet. By itself, it only provides a small window, but even during that small window, the amount of traffic was quite great. And even with a glance, it is clear that this was the place for exchanging ideas and for sharing important knowledge.

Even by June 1981, though, the size of the list and the volume on it had increased to an unexpected level. A message from "The Moderator" with the subject "Submissions to Human-Nets" notes that he has received complaints about the "randomness" of the topics, and he asks members to remember that messages will be read by 3,000 people. In particular, he apologizes for allowing the discussion on socalled left-handed sugar (meaning no-calorie sugar, left-handed being a description of its molecular structure). It has become clear how exuberant participants felt about the conversations they were having. He noted that he would be leaving the post of moderator because he had taken a job elsewhere. Jorge Phillips, nevertheless, disagreed that the conversation had become too far ranging:

Even if we have shifted away from discussing human networks, we are getting a first-hand EXPERIENCE of what they are through this mailing list. No amount of "a priori" theorizing of their nature has as much explanatory power as personal experience. By observing what happens when connectivity is provided to a large mass of people in which they can FREELY voice their ideas, doubts, and opinions, a lot of insight is obtained into very important issues of mass intercommunication. The fact that such dissimilar [sic] topics as antimatter, left-handed sugar, the telephone network, etc. have been discussed in our own instance of a human network says a lot about its nature and the interests and nature of its members and should not be considered as detracting from the quality of the discussion.

The discussion about what to discuss would continue as the list grew in size. As seen in Figure 1, Volume 3 had 122 email messages and Volume 5 had 176 emails. This was due to the fact that Volume 3 was only partially complete. However, what is interesting is the increased number of emails in the "Help" and "Human/Computer 
Interaction" categories. Meta discussions were the least numerous but a qualitative looks reveals that they were of historical significance.

The conversation later often ranged into a discussion about what was acceptable use for a computer network. For instance, in early 1985 a dilemma regarding STARGATE, a satellite transmission service for USENET, boiled over onto HUMAN-NETS. A message describing STARGATE was originally written by a user of USENET, describing the plan to save transmission costs by hiring a satellite to gather messages for USENET and rebroadcast them directly to local networks, replacing the current store-and-forward method. However, as the proposal evolved, network administrators suggested that the messages should be moderated before they were sent to the satellite for rebroadcast, eliminating the "garbage," causing a change in the free-wheeling conversation that USENET users had become accustomed to. Because he thought that it would spark a useful conversation on HUMAN-NETS, an ARPANet user forwarded the message. In a period of three months, fifteen messages were sent, in a period where the total volume of the list was about fifteen messages a month. The conversation, which of course was sent back to USENET in broadcastonly mode, reveals the depth of awareness that users had about the power of electronic messaging conversation and the reasons why this proposal would be unfavourable, while at the same time maintaining a thoughtful awareness of the issue of liability that were inherent to a broadcaster, like a television network, as opposed to a common carrier, such as a train or telephone service.

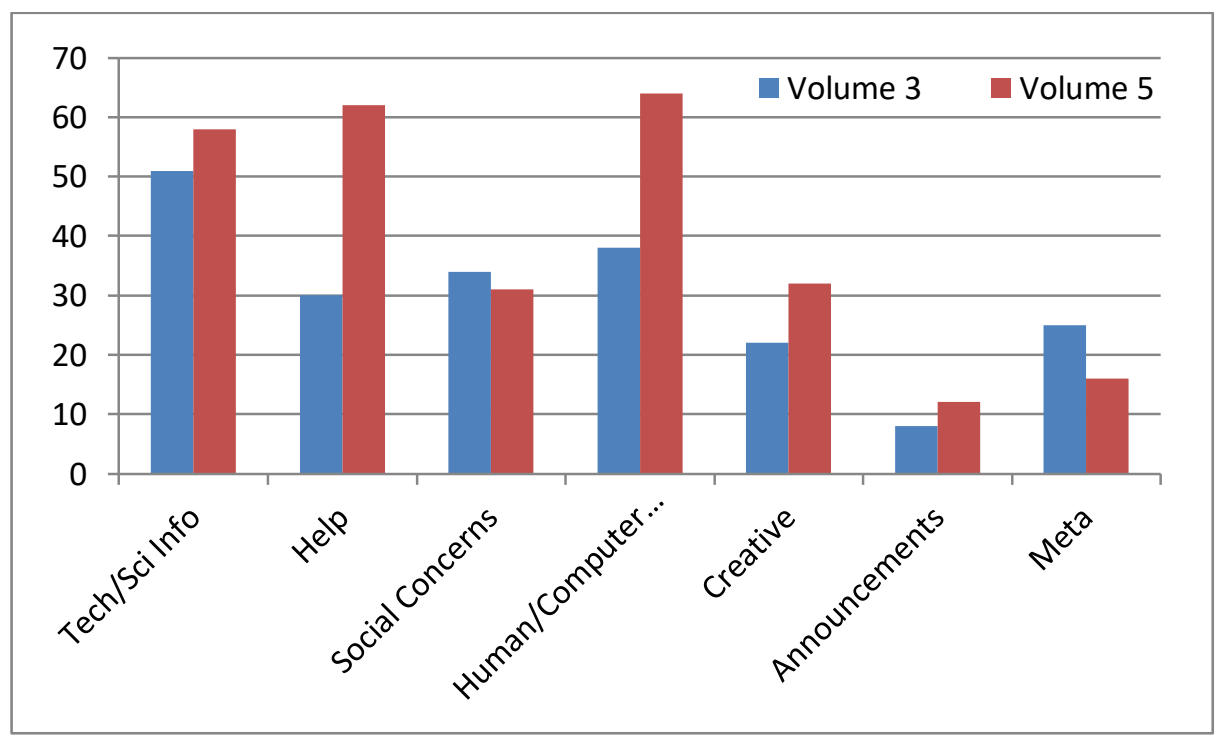

Fig. 1: Types of Discussion on Human Nets in 1981 (Volume 1) and 1983 (Volume 3)

The increase in emails asking for help reflects the influx of new users between 1981 and 1982. The content of the discussion came to be more software and programming oriented rather than hardware oriented. The increase in emails 
discussing human and computer interaction can be accredited to growing interest in videogames as well as attempts to create more ergonomic designs. In fact, the number of emails discussing videogames increased significantly in Volume 5. One of the more interesting emails discussed the idea of sex in videogames and inventing a reallife sex doll. Ironically, the email ended in "I hope no one takes this seriously."

Another prevalent assumption by the mailing lists moderators was that advertising for a private company should not be allowed on the mailing lists. Surprisingly, one of the army personnel cleared up the issue in 1986. Wrote Will Martin from the US Army Materiel Command Automated Logistics Management Systems Activity:

If you are putting out some product info for altruistic reasons, for the good of others or to warn them away from trouble, and have no personal interest in the success or failure of the vendor that offers that product, you can post *anything*. That includes prices, specs, sources of supply, evaluations, rumors, what-have-you.

The biggest numerical change from Vol. 3 to Vol. 5 was the increasing discussions about human and computer interactions. These discussions ranged from video games to using computers to weave. There were also quite a few requests for help. However, unlike Vol. 3, most people had questions concerning software. Vol. 5 takes place in 1982, from August until December. It is quite larger and has much more content. Both numbers for human computer interaction discussions and social concerns discussions rose significantly. There was still a large amount of discussions about computers and such, but it did not scale up. The majority of the technological discussion was about the World-Net, about how it should be implemented and the cost of doing so. The human computer interaction discussions were centred on video games, working at home, getting people to use computers and weaving. The social concerns discussions were mostly about censorship on TV.

The possibility of networks coming together to form a global network was on the minds of many users at the time. The discussion focused mostly on the cost analysis, prospective line-layer, and the protocols. One of the arguments was about whether or not the network should be owned by one company, namely Bell. The argument was that Bell had the best service at the time, but doing so could exclude the rest of the world. TCP/IP was already being used to connect the existing networks and the whole system was working without AT\&T already. It was also argued that one company should not have the power to shut down a communication network. Notably, the idea of World-Net had been already explored in the novella by Vernor Vinge, True Names [22]. In the story, written in 1980, a megalomaniac takes over the world's interconnected bulletin board system.

The discussions about video games focused mainly on which games were available and how to access them. The most interesting part about the video game conversation was about the banning of Atari adult video games. Ironically, someone pointed out the possibility of selling sexware/sexbots. At the other end of the spectrum, one suggests using video games in a nursing home as entertainment, to make the elderly less miserable. A more serious discussion was on working at home via a computer. There were a few who were already doing so and they were 
discussing the pros and cons of it. This brought up the problem of using the sole phone line for online connection. There were those who relied on call waiting and suffered, and then there were those who paid for four lines. The discussion on how to get non-technical people to start using computers generated both good and bad ideas, from using video games to taking away office equipment. The discussion on using computers in weaving did not seem to hold much significance. It was simply a discussion between a few hobbyists exchanging miscellaneous information about weaving history and the technical part of using computers to design and make weaves.

The discussion on censorship in TV also continued for a while. Apart from the typical arguments and statements, the majority of the emails seemed to be against censorship. This seems to be a continuing trend on the mailing lists. On the issue of first amendment, the users of ARPA-Net seemed to always support it. This sort of controversy pops up over and over again, but always the users spoke for free speech. The increase in the number of software questions could be due to a number of factors. The hardware could have become more standardized and did not require much helping. The moderator could have chosen to not send out a repost email. The digests were available and were already helping out. It could also be accredited to CS gaining momentum. One of the surprising discussions in this volume was a discussion of a professor who taught computer science.

As the network and computers became more available to the general public, the researchers became more concerned about the effects of this new technology. They also wanted to play games. The possibilities were endless for them. In fact, they were discussing the idea of a game with different paths and possibilities, similar to that of a modern RPG. They did not want a powerful entity to control the new tool of communication. It was their playground. The censorship in video games and TV demonstrated the public's more conservative ideals. Although, the majority of the emails expressed disdain for censorship, the idea of using computers for sex was not taken seriously back then. The discussion about telecommuting shows a growing interest and opportunity for work at home jobs. However, the technology at the time was not prepared for such advancement. The requirement for multiple phone lines for the sake of convenience was too expensive for a lot of people. But because this was brought up, it certainly would have informed many of the benefits and the difficulties of working at home.

Interestingly, the announcements were not as administrative in Vol. 5. There were several calls for papers and thesis, indicating a reliance of the net for academia. The announcement for a conference, indicating drunkenness and questionable behaviour, was rather surprising. But this demonstrates a growing trend toward more public and social usage. In simply a year's amount of time, Human-Nets had evolved toward a more social oriented nature. But with the diversification of topics, it will have to divide up to accommodate the increasing number of people using the net, discussing more and more irrelevant topics. 


\section{From ARPANet to CSNET}

This background of ARPANet user aspirations is an important precursor to understanding the international push in the development of CSNET. Although it was short-lived, CSNET offers Internet history some interesting examples of how networking environments were created to suit an international environment. The boisterous, collegial community witnessed on HumanNets became the envy of those who were not working on military contracts and, therefore, were not granted access. CSNET was an effort to bring the public sphere developed accidentally on ARPANet to the academic community.

Several innovations - the idea of a logical, autonomous network, the nameserver service, and also the important experience for the NSF - can be tied to CSNET. Another important example offered by CSNET is its networking that was conceived as an autonomous network that would connect to ARPANet. Although one could argue that these autonomous networks was what led to the development of a rich environment for networking, it will be of course the autonomy of these networks that will facilitate Internet filtering in the years following. Landweber's proposal was made shortly before the "Great Switch" to TCP/IP and the establishment of DNS in 1983, and so CSNET is an example of the philosophy of independent networks being connected by a single protocol. As noted by David Clark [23] in his essay on the development of Internet protocols, TCP/IP was an effort to join "separately administered" networks with a common protocol. In this way, CSNET is thought of as a "logical network" that was composed of several different physical networks [24] and is an example of what the Internet is like today; software was used to create a seamless experience for the user so that he or she does not recognize that information is traversing separate physical networks. The gateway between CSNET and ARPANet would be enabled by the newly-developed internetworking protocol developed by Vinton Cerf and Robert Kahn, TCP/IP. The central place CSNET had in his conversation is reflected by the specification of DNS described in RFC 883 (Nov. 1983), where CSNET is one of three domains, along with .ARPA and .DDN. In this way, CSNET is an early example of an autonomous network connected by a gateway.

Another aspect of this story that is interesting is the freedom and authority it gave to Landweber himself. Many researchers on the international scene credit their start in networking by attending a seminar with Landweber, a series that came to be known as "Larry's Networkshops." The first seminar was held in London in 1982, where Germany described its research network, active projects in Norway and Sweden were described, the SERCNet Coloured Book protocols from the United Kingdom were presented, and researchers from CERN described what would become HEPNet [25]. As this list suggests, networking was already an international phenomenon - what was missing was a mechanism to bring these different networks together. At the second meeting of Larry's Networkshop in 1983, Landweber announced that CSNET would become international. Israel got a PhoneNet connection in 1984, followed by Korea and Canada. Australia, France, and Germany join later. Soon, Israel, Korea and Japan get full IP access. The 1987 meeting in Princeton brought together the top 100 international networking researchers. A CSNET site list [26] distributed in 1988 
(Table 1) gives a glimmer of understanding of how CSNET was able to bring together international researchers by connecting their local networks.

As an example of what this looked like on the ground, Germany was establishing its own computer networks concurrently with these developments. Although Germany was not connected to CSNET until 1984, the beginning of international connections came to Germany in the form of a DATEX-P connection from the University of Cologne to Amsterdam as part of the European EARN network. This connection was based on a dedicated line and was fairly expensive to use, but from this connection it was possible to send and receive electronic messages through the CSNET gateway at the University of Wisconsin. Having a connection was just a small aspect of the Internet, but one could receive RFCs about TCP, IP, telnet, FTP, find instructions on how these new protocols could be implemented on a variety of services, and print them out in a computer centre [27].

Table 1: CSNET Site List

\begin{tabular}{|c|c|c|}
\hline Service & Domain & Description \\
\hline Internet & +ean.ubc.ca & $\begin{array}{l}\text { U. of British Columbia - Vancouver, BC, Canada. } \\
\text { Gateway to CDNNET and EAN networks }\end{array}$ \\
\hline Internet & nss.cs.ucl.ac.uk & $\begin{array}{l}\text { University College - London, England, UK. } \\
\text { Gateway to JANET (ac.uk domain) and PSS }\end{array}$ \\
\hline PhoneNet & munnari.oz.au & $\begin{array}{l}\text { U. of Melbourne - Parkville, Victoria, Australia. } \\
\text { Gateway to "oz" (oz.au domain), other hosts }\end{array}$ \\
\hline Phonenet & chalmers.se & $\begin{array}{l}\text { Chalmers U. of Technology - Gothenburg, } \\
\text { Sweden. Gateway to SUNET (Swedish U. } \\
\text { Network) }\end{array}$ \\
\hline Phonenet & zix.gmd.dbp.de & $\begin{array}{l}\text { Deutsches Forschungsnetz }- \text { Berlin. Federal } \\
\text { Republic of Germany, Gateway to DFN network }\end{array}$ \\
\hline Phonenet & hut.fi & $\begin{array}{l}\text { Helsinki U. of Technology - Helsinki, Finland. } \\
\text { Gateway to FUNET (Finnish U. network) }\end{array}$ \\
\hline Phonenet & inria.inria.fr & $\begin{array}{l}\text { INRIA - Rocquencourt, Le Chesnay CEDEX, } \\
\text { France. Gateway to COSAC (French National } \\
\text { Network) }\end{array}$ \\
\hline Phonenet & ira.uka.de & $\begin{array}{l}\text { U. of Karlsruhe - Karlsruhe. Federal Republic of } \\
\text { Germany, Gateway to DFN network }\end{array}$ \\
\hline Phonenet & +utokyo-relay\# & $\begin{array}{l}\text { U. of Tokyo - Tokyo, Japan. Gateway to JUNET } \\
\text { (Japanese U. Network) }\end{array}$ \\
\hline Phonenet & sorak.kaist.ac.kr & $\begin{array}{l}\text { Korea Advanced Inst. of Science and Technology - } \\
\text { Seoul, Republic of Korea, Gateway to SDN } \\
\text { network }\end{array}$ \\
\hline Phonenet & waikato.ac.nz & Waikato U. - Hamilton, New Zealand \\
\hline Phonenet & ifi.ethz.ch & $\begin{array}{l}\text { ETH-Zentrum - Zurich, Switzerland. Gateway to } \\
\text { CHUNET (Swiss U. Network) }\end{array}$ \\
\hline X.25 dialup & huji.ac.il & $\begin{array}{l}\text { Hebrew U. - Jerusalem, Israel. Gateway to ILAN } \\
\text { network }\end{array}$ \\
\hline
\end{tabular}


In 1984, with Germany having already seven years' experience with networking computers but little connectivity to international networks, Werner Zorn, the chair of computer science at Karlsruhe University in the southern part of West Germany, articulated the need for Germany to establish international connections. On August 2, 1984, Zorn and a colleague at the University of Karlsruhe sent what has come to be known as the first e-mail from Germany, a reply to the message from Landweber at the University of Wisconsin welcoming him to CSNET [28]. West Germany was the only the fourth country to join CSNET, following Canada, Sweden, and Israel. Karlsruhe became the node for messages entering and leaving Germany, quickly adding connections to universities such as Fraunhofer and the Max Planck Institute, as well as members of the business community with connections to Siemens and BASF. Through this connection it was much easier for computer scientists and engineers to communicate with their international counterparts as well as access the growing amount of information that was available online. It became clear that the demand in Germany for international access was high, and in 1985 a research association was created, Deutsche Forschungsnetz [29]. Thus, Table 1 lists Berlin's DFN as the location for the German connection to CSNET in 1988.

Missing from Table 1, however, is the connection that Germany makes with China, and this tells an important aspect of the internationalization of the Internet. The technology behind the connections was made by scientists seeking to help others; individuals had to make the world ready for the Internet before the Internet was ready for the world. Qiheng Hu, chairwoman of Internet Society of China and the Chinese Academy of Engineering (CAE), points out [30] that the first TCP/IP connection was established long after national networking in China had begun. In a presentation to honour the $20^{\text {th }}$ anniversary of the first e-mail sent from China, she detailed the extent of networking experiments, not to diminish the German effort, but so that her audience has "the feeling about the hungry and thirsty status, especially from the science and technology community in China." In March 1980, the Chinese Academy of Construction Research created an online international retrieval terminal established in Hong Kong, which provided trial retrieval services to Chinese institutions. In December 1981, the Information Institute for Computer Applications set up an international online terminal through fax lines in Beijing using leased satellite lines through ARPANet to connect to the DIALOG database, an information retrieval and bibliographic database now owned by ProQuest. In October 1983 the Institute of Information of China (now Institute of Science and Technology of Information of China) connected to the European Space Agency Information Retrieval System via satellite link and connected through Italy Public Data Network to the US Public Data Network. From there, China was connected to twelve information systems of different countries. On July 1, 1984, the Institute of High Energy Physics set up a time-sharing terminal with microwave transmission with the M-160 at the China Institute of Water Resources and Hydropower Research (IWHR), a distant terminal of the M-160 because the IHEP did not have computer power for large-scale modelling. The extent to which China's computers could access international information as described by Hu is striking; by 1985, China had over 50 international online retrieval terminals set up. These were all dedicated connections to proprietary services, however. 
Given the already strong setup of Chinese computer networks and the prevalence of international connections, it may seem strange that Germany is credited with connecting China to the international computer networks so that it could send a mail message in 1987. (As noted by Jay Hauben [31], Zorn is not always given credit for this development.) Although the choice of Germany as a partner may not seem obvious, it makes sense in the context of Cold-War prohibitions on the export of high technology to China from the United States. The genesis of the project was when 18 universities received Siemens computers in a project sponsored by the World Bank $[32,33]$. To assist China's use of its computers, the Scientific Siemens User Group had sent 15 people from Germany to China for the WASCO Symposium on September 12, 1983. The German researchers presented trends of the future of networking and practical questions of how to set up computers to make networks happen. Werner Zorn, the computer science professor at the University of Karlsruhe who connected Germany to CSNET, made a presentation on the way in which OSI protocols could be used to operate a network in China. After the symposium, Zorn's new CSNET connection to the United States made it painfully clear to Zorn how difficult it was to communicate with China. Planning for the second WASCO symposium for the fall of 1985 meant that one had to allow for a 14-day turnaround for all communication to China, because telephone and telex were so expensive. It was clear that an Internet link would improve matters greatly, but there were two difficulties: one being money to put it together, the other being the U.S. ban on exports of technology to China. The ban on exports did not affect Germany directly, but there was a concern that should Germany help China develop Internet connections, it might disturb the U.S. government.

Money for the German side of the link to China came from the prime minister of the German state Baden-Wittemberg that same year. Zorn decided that the best way to avoid the appearance of exporting U.S. technology to China was to set up a physically separate link from Germany to China with German equipment and software, and then connect China to CSNET in Germany. For this purpose, Zorn obtained a $\mu$ VAX II and set it up using Unix 4.2, a good choice because UNIX was popular in China and it made possible a Unix to Unix Copy (UUCP) connection, which is the file transfer protocol behind USENET. It was not possible to obtain funds for a similar computer on the Chinese side, so Zorn decided to follow an alternate plan and set up a dialup connection from China to Karlsruhe. He arranged a two-week lecture and project trip for May 1986 and took the equipment needed for the connection - basically a modem and software - to China as excess baggage.

Setting up a dialup link from China was not as easy as it may sound. Telephone calls in China were, for the most part, locally connected and sometimes a caller had to wait as long as an hour for a line. What Zorn needed was a permanent line from the computer centre to the local phone exchange, but this was not likely to happen in an environment where an entire residential area had access to only one phone line. It did not seem like a dialup connection was going to work, but then he learned that there was an X.25 network connection to a nearby university that connected via satellite to Italy. Using X.25 as the lower-level protocol, Zorn was able to set up a connection back to Germany; the idea of sending TCP/IP packets over X.25 connections, of 
course, had already been established for middle-tier CSNET users and he had implemented this solution on Siemens computers in Germany. With this connection established, messages for China would be held at the Karlsruhe computer and collected remotely from China at periodic intervals.

In setting up this link, Zorn suggests that from the technical side he did very little. The colleagues at ITALCABLE (the Italian network connection) had already done the real work. Even though Karlsruhe received a lot of publicity for the connection, "our contribution actually lay in being fortunate enough to find and pave a way via the different entities involved" [32]. However, from the perspective of the history of the Internet, Zorn's contribution was quite essential. In spite of the many international data connections that were established in China, there had not yet been this kind of flexible connection. Proprietary systems using their own protocols were set up, but these only allowed for specific networking solutions. The end-to-end resource established by TCP/IP was missing.

In the summer of 1987, while preparing for the next symposium in Beijing, Zorn asked Larry Landweber for permission to connect China - in particular, to install the BS2000 software they had used on their own Siemens computer to connect to CSNET. "Larry's view on this was totally positive," and Zorn had his permission to go ahead [32]. At a symposium to celebrate the twentieth anniversary of the first email from China, however, Landweber told Zorn a slightly different story. Landweber notified Zorn immediately when permission was given from the National Science Foundation, but the next day he was notified that the connection had been denied by the White House and connection should be turned off. Thinking of these events, Landweber characterizes the philosophy of Stephen Wolff, who was director of the U.S. National Science Foundation Division of Networking and Communications Research, which was 'you don't ask permission in advance. You ask for forgiveness later" [34]. The academics decided that they would continue with the project; as noted by Jay Hauben, the official approval for this connection was granted retroactively in November [35].

The "First Electronic Mail from China to Germany" was sent on Monday, 14 Sep 87 in German and English by Michael Finken, the graduate student Zorn had left behind to finish the installation. In the same way that the connection to international computer networks inspired Germany to strengthen its connection to the Internet, computer science researchers in China were motivated by the connection to CSNET and founded the Chinese CANET in March of the next year. Due to this personal effort, China's national network was connected even earlier than Canada's.

\section{Conclusion}

Although one might be accustomed to thinking about the diffusion of the Internet especially across international boundaries - as one of a good idea catching like wildfire, the preceding analysis has shown that the diffusion resulted from a pull as much as a push. What is more, the dream of the international connections possible by the Internet predate even the implementation of TCP/IP itself. 
In his analysis of USENET, Michael Hauben has pointed out that USENET was a reliable network. By this, he did not mean that its protocols or hardware were more robust than other possibilities; he says that USENET existed and survived due to the determination of its users. It was strong because it was "a peer to peer network" that individuals looked after. As I hope this paper has shown, the earliest protocols of the Internet were developed and supported by a similar mind-set. It was only by the cosmopolitan outlook of individual researchers that these connections were made. This is not a side example; Bernard Aboba has pointed out that the Internet was international from the start [36]. In spite of the way the history of the Internet is frequently told, CSNET, nor NSFNET, did not "cause" international networking and nor was it the case that countries outside the United States were ignoring the possibilities the computer networking could provide. In fact, quite the opposite is true. International computer networks existed alongside the development of TCP/IP, and in fact it was an international outlook that led to the flexibility of the protocol, as noted by Clark.

When the story told about the Internet is one of technical and administrative innovation, it can safely be elided from the history of the Internet. What has been missing is a sense of why Internet advocates were interested in creating this diverse network that was not defined by participation in military research. The international identity of its innovators explains why these early innovations were important beyond their technical innovations: the idea of international cooperation among the designers and users of the early Internet was essential in deploying a flexible network that could provide worldwide connectivity. By looking at the interests and ideas of the users and advocates of the Internet, one can find user communities that define themselves as members of a community of diverse networks, an attitude that would be a marker of the eventual success of the Internet.

Acknowledgement. Grateful acknowledgement is made to Aye Muang who, as an undergraduate research student, conducted the evaluation of Human-Nets. He and the author are indebted to the New York University Tandon School of Engineering Undergraduate Summer Research Program and its founder, Associate Dean Iraj M. Kalkhoran, which provided Aye a stipend that supported this research.

\section{References}

1. Man, John. Gutenberg: How One Man Remade the World with Words. New York: Wiley. (2002)

2. Hafner, Katie and Matthew Lyon. Where Wizards Stay Up Late: The Origins of the Internet. New York: Touchstone. (1996)

3. Brunton, Finn. Spam: A Shadow History of the Internet. Cambridge: MIT Press. (2015)

4. Warrick, Patricia S. The Cybernetic Imagination in Science Fiction. Cambridge: MIT Press. (1980)

5. Abelson, Alan. "Up \& Down Wall Street" Barron's National Business and Financial Weekly (Feb 12): 1, 33-34. (1979) 
6. "The Months Ahead." Changing Times 32.6 (June): 5. (1978)

7. McLean, Gary N. "Curriculum Implications of the Office of the Future: Or, Projected Implications - More (or Less) Accurate.” The Journal of Business Education 56:7: 268271. (1981)

8. Abbate, Janet. Inventing the Internet. Cambridge, MA: MIT Press. (1999)

9. Shapin, Steven and Simon Schaffer. Leviathan and the Air-Pump: Hobbes, Boyle and the Experimental Life. Princeton, NJ: Princeton University Press. (1985)

10. Oudshoorn, Nelly and Trevor Pinch, eds. How Users Matter: The Co-Construction of Users and Technology. Cambridge, MA: MIT Press. (2003)

11. Lundin, Per. Computers in Swedish Society: Documenting Early Use and Trends. New York: Springer (2012)

12. Landweber, Lawrence H. "CSNET, the Computer Science Research Network: Proposal to the National Science Foundation." Accessed on 2 October 2012 from http://world.std.com/obi/CSNET/ (1980)

13. McKenzie, Alexander A. and David C. Walden. "ARPANet, the Defense Data Network, and Internet." The Froehlich/Kent Encyclopedia of Telecommunications. Fritz E. Froehlich, Allen Kent and Carolyn M. Hall, eds. New York: Marcel Dekker. (1991)

14. CSNET. "Project Status Report." Accessed from http://world.std.com/obi/CSNET/ (1982)

15. Internet Society. "Trailblazing CSNET Network Receives 2009 Jonathan B. Postel Service Award." Accessed from https://www.internetsociety.org/news/trailblazing-csnetnetwork-receives-2009-jonathan-b-postel-service-award on 12 April 2016. (2009)

16. Hauben, Ronda. "ARPAnet.” Accessed 12 April 2016 from http://www.columbia.edu/ rhauben/CS/arpanet-encyc.txt

17. Griffiths, Richard T. "Chapter 3: History of Electronic Mail.” Accessed 12 April 2016 from http://www.let.leidenuniv.nl/history/ivh/chap3.htm (2002)

18. Lynch, Keith. "Re: History of the Net is Important." Accessed 12 April 2016 from http://keithlynch.net/history.net.html (1994)

19. Wikibooks. The Computer Revolution/The Internet Revolution. Accessed 16 April 2016 from http://en.wikibooks.org/wiki/The_Computer_Revolution/The_Internet_Revolution (2012)

20. Archives of Human-Nets are available online from various websites, such as the one at http://www.cs.rutgers.edu/ cwm/NetStuff/Human-Nets/ accessed 2 October 2012.

21. Earnest, Les. "A Look Back at an Office Of The Future." Decision Support Systems: Issues and Challenges. Göran Fick and Ralph H. Sprague, eds. Elmsford, New York: Pergamon Press. Accessed 16 April 2016 from http://www.iiasa.ac.at/Publications/ Documents/XB-80-512.pdf (1980)

22. James Frenkel, ed. True Names and the Opening of the Cyberspace Frontier. New York: Tor. (2001)

23. Clark, David D. "The Design Philosophy of the DARPA Internet Protocols." Proceedings of SIGCOMM 88 Conference on Communications Architectures and Protocols: 106-114. (1988)

24. Comer, Douglas. "The Computer Science Research Network CSNET: A History and Status Report." Communications of the ACM 26.10: 747-753. (1983)

25. Malamud, C.: Exploring the Internet: A Technical Travelogue. Prentice Hall, Englewood Cliffs, NJ (1993)

26. CIC. "CSNET Site List." Accessed 2 October 2012 from http://www. mit.edu/afs.new/athena/reference/net-directory/host-tables/csnet.site-list (1988) 
27. Netplanet.org. "Das Internet in Deutschland." Accessed on 2 October 2012 from http://www.netplanet.org/geschichte/deutschland.shtml (1998)

28. Deutsche Welle. "Germany Celebrates 20 Years of E-Mail." Accessed 12 April 2016 from http://www.dw.com/en/germany-celebrates-20-years-of-e-mail/a-1284655 (2004)

29. Kalle, Claus. "Das Internet in Deutschland - Ein alter Hut?" Kompass 64 (18 July). Accessed online on 2 October 2012 from http://mikro-berlin.org/Events/OS/reftexte/kalle/OInetinDland.html. (1995)

30. Hu, Qiheng. "Growth of the Internet in China since 1987." Deutschland und China Innovationspartner in der Informationstechnologie. Accessed online from http://www.tele-task.de/archive/video/real/1412/ on 2 October 2012. (2007)

31. Hauben, Jay. "The Story of China's First Email Link and How it Got Corrected." Address at the International Conference on Media Education and Global Agendas. $\begin{array}{llllll}\text { Accessed online } & \text { on } 2012 & \text { October }\end{array}$ https://www.informatik.kit.edu/downloads/HaubenJay-ChongqingSpeech-12Jan2010.pdf (2010)

32. Zorn, Werner. "How China was Connected to the International Computer Networks." Amateur Computerist Newsletter 15.2. Accessed online 2 October 2012 from http://www.ais.org/ jrh/acn/acn15-2.articles/zorn.pdf (2007)

33. Zorn, Werner. "China's CSNET Connection 1987 - origin of the China Academic Network CANET." Asia Internet History Project. Accessed online on 2 October 2012 from https://sites.google.com/site/internethistoryasia/book1/personal-essay-werner-zorn (2012)

34. Jennings, Dennis. "Panel Discussion: The Impact of the First E-mail." Deutschland und China - Innovationspartner in der Informationstechnologie. Accessed online from http://www.tele-task.de/archive/video/real/1412/ on 2 October 2012. (2007)

35. Hauben, Jay. "“Across the Great Wall': The China-Germany E-mail Connection 19871994." The Amateur Computerist 13.1 (Spring): 25-29. (2005)

36. Aboba, Bernard. "How the Internet Came to Be, Told by Vinton Cerf." The Online User's Encyclopedia. Addison-Wesley. Accessed online from www.virtualschool.edu on 2 October 2012. (1993) 